\title{
Going in Reverse to Go Forward
}

\author{
By Jack M. Gorman, MD
}

In most medical specialties, detailed knowledge of the normal anatomy, physiology, and histology of the organs of interest were known before the specifics of disease states were revealed. Long before it was understood that tiny plaques clogging coronary arteries is the proximate cause of myocardial infarction, the fact that a heart has four chambers that work in concert to pump blood throughout the circulatory system was well-known.

In psychiatry, and to some extent neurology, we have tried to do things in the opposite direction. We want to know what a brain is like in someone with depression, schizophrenia, panic disorder, or multiple sclerosis. However, what do we really know about the normal function of the central nervous system? We really do not know what the brain actually does that is associated with someone feeling happy or sad, calm or anxious. Many of the details of how the brain lays down myelin, the target for multiple sclerosis, are still unknown. In essence, we have tried to skip over an understanding of normal brain function and jump right into wanting to know what causes serious and complex brain diseases. The result has not been a whopping success.

This month's CNS Spectrums, guest edited by Israel Liberzon, MD, features articles on what neuroscientist Joseph E. LeDoux, PhD, ${ }^{1}$ has called "the emotional brain." LeDoux has spent a lifetime trying to understand what happens in the brain during one typical and normal emotion, fear. Thanks to him and other scientists like Michael Davis, $\mathrm{PhD}$, and Trevor $\mathrm{W}$. Robbins, $\mathrm{PhD}$, we now know in great detail the neuroanatomy, physiology, and cellular and molecular biology of at least one type of fear, conditioned fear. From this basic knowledge, gained only by years of painstaking work at the laboratory bench and later by neuroimaging studies of normal human volunteers, the field has now moved toward understanding what happens when normally expressed fear becomes pathological, resulting in anxiety disorders.
This is clearly a strategy that we need to follow more extensively in our search for causes and cures of psychiatric and neurologic disease. Studies are now underway, for example, to better understand the normal aging process in animals and humans as a basis for learning more about Alzheimer's disease. A group led by Daniel Weinberger, $\mathrm{MD},{ }^{2}$ at the National Institute of Mental Health recently showed that naturally occurring polymorphisms in the gene encoding the enzyme catechol-O-methyltranferase affect memory and prefrontal cortical activation in normal individuals.

A study recently published by Tor $\mathrm{D}$. Wager, $\mathrm{PhD}$, and colleagues ${ }^{3}$ showed brain regions that are activated in normal individuals by pain and by the belief that they had been given an analgesic medication, which was actually a placebo. All of this research helps us understand how the normal human brain operates, even when it performs operations and experiences emotions for which we either have no viable animal models or know for sure that animals are not capable of performing or experiencing.

It is a cliché, of course, to state that the brain is the organ of interest for psychiatrists and neurologists. It is surprising, however, how very little we know about its basic operations in normal, daily activity. For those reasons, we should welcome the kind of work represented by the articles in this month's CNS Spectrums and hope that it helps encourage much more work in this area. CNS

\section{REFERENCES}

1. LeDoux JE. The Emotional Brain: The Mysterious Underpinnings of Emotional Life. New York, NY: Simon \& Schuster; 1998.

2. Goldberg TE, Egan MF, Gscheidle T, et al. Executive subprocessess in working memory: relationship to catechol-O-methyltransferase Val1158Met genotype and schizophrenia. Arch Gen Psychiatry. 2003;60:889-896.

3. Wager TD, Rilling JK, Smith EE, et al. Placebo-induced changes in FMRI in the anticipation and experience of pain. Science. 2004;303:1162-1167. 